\title{
Target Data Association Using a Fuzzy-Logic Based Approach
}

\author{
Stephen Stubberud ${ }^{1}$ and Kathleen Kramer ${ }^{2}$ \\ ${ }^{1}$ Rockwell Collin, \\ 2 University of San Diego \\ USA
}

\section{Introduction}

Level 1 data fusion is defined as object assessment (Hall \& Linus, 2001). This process of estimation and prediction of an entity can be decomposed into a functional series of subprocesses as defined by the well known Bowman model (Steinberg, et al, 1999) that is depicted in Figure 1. While data fusion can apply to a host of applications, this chapter looks at the problem from a target tracking point of view.



Fig. 1. Fusion Architecture Based upon the Bowman Model.

In tracking, the object, a potential target, can be considered to have two descriptive state vector elements: kinematics (e.g., position, velocity, etc.) and classification. These state vectors are generated based upon the information provided by a host of sensors over time. When a single target is present, this problem is straightforward. When multiple targets exist in the region of interest, however, the association subcomponent of Figure 1 becomes the key element of the process. Data association, sometimes referred to correlation, is the process of determining the correct target object to relate to each measurement. In Figure 2, multiple sensors along with a number of targets appear in the region interest. The reported kinematic measurements from all the sensors are shown in Figure 3. The association step of the fusion process determines which measurements are from the same target. This process is repeated each time a sensor reports measurements to the fusion system. In addition to issues with the number of targets and sensors reporting, each sensor has a degree of uncertainty associated with it. Instead of each measurement being expressed as a crisp point or even a line of bearing, uncertainty in the measurement creates a region of varying shape and size that depends on the type of sensor measurement and the sensor's accuracy is created. These regions, usually described as probability density functions, then interact with probability density functions that describe the target's kinematic track information. 
To generate the associations between targets and measurements and between measurements of different sensors, association scoring routines have been developed. Since the measurements are described as random variables, as are the fused target tracks, the association algorithms are often based on a probabilistic measure. Most often, the association is based on the joint probability of the distance between the measurement and predicted location of the target based on the last known position and its velocity information:



Fig. 2. Multiple sensor platforms in a region with multiple targets

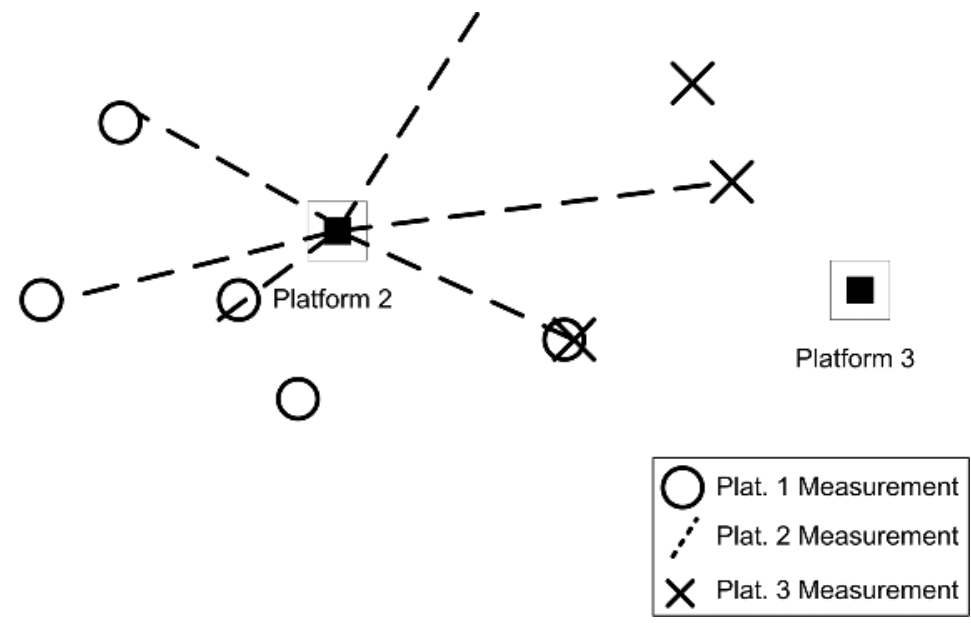

Fig. 3. Resulting reported kinematic measurements from platforms 
where the bounds for the calculating the probability are based an estimate of the error in the target location prediction. Often, the track state estimate is computed using a Kalman filter (Blackman, 1986), (Blackman \& Popoli, 1999), (Barshalom \& Li, 1993). This implies that the measurements and the track states are Gaussian random vectors. When this assumption is used, a simplified distance measure, referred to has the Mahalanobis distance (Blackman \& Popoli, 1999),

$$
\chi^{2}=\left(\mathbf{h}\left(\mathbf{x}_{1}\right)-\mathbf{z}_{2}\right)^{T}\left(\mathbf{H P H} \mathbf{H}^{T}+\mathbf{R}_{2}\right)^{-1}\left(\mathbf{h}\left(\mathbf{x}_{1}\right)-\mathbf{z}_{2}\right)
$$

is used. The values $\mathbf{R}$ and $\mathbf{P}$ denote the measurement error covariance and the state error covariance, respectively. This weighted distance is computed in the measurement space. The coordinate transformation from the track state-space to the measurement space is through the output-coupling function

$$
\mathbf{z}_{1}=\mathbf{h}\left(\mathbf{x}_{1}\right)
$$

and its associated Jacobian

$$
\mathbf{H}=\left[\begin{array}{llll}
\frac{\partial \mathbf{h}}{\partial x_{1}} & \frac{\partial \mathbf{h}}{\partial x_{2}} & \cdots & \frac{\partial \mathbf{h}}{\partial x_{n}}
\end{array}\right]^{T}
$$

The distance is a unitless value and is a chi-squared random variable. As such, the Mahalanobis distance is sometimes referred to as the chi-squared metric. For some applications in tracking, the chi-squared metric is normalized between 0 and 1 as either a non-metric

$$
e^{-\left(\mathbf{h}\left(\mathbf{x}_{1}\right)-\mathbf{z}_{2}\right)^{T}\left(\mathbf{H P H} \mathbf{H}^{T}+\mathbf{R}_{2}\right)^{-1}\left(\mathbf{h}\left(\mathbf{x}_{1}\right)-\mathbf{z}_{2}\right)},
$$

where 1 indicates perfect association and 0 indicates no association, or as a normalized metric

$$
1-e^{-\left(\mathbf{h}\left(\mathbf{x}_{1}\right)-\mathbf{z}_{2}\right)^{T}\left(\mathbf{H P H} \mathbf{H}^{T}+\mathbf{R}_{2}\right)^{-1}\left(\mathbf{h}\left(\mathbf{x}_{1}\right)-\mathbf{z}_{2}\right)},
$$

where the reverse is true.

Often, the probability association score of Eq. (1) can be considered computationally complex for real time calculations. One reason for this is that the density function can also be dependent on the reported mean value of the target location, i.e., near field effects. Also, each target track's density function is recalculated for each update with a new measurement. Eq. (1) does clearly allow for modeling of the sensor anomalies and blockages that can occur. The boundary could be quite complex. Piece-wise linear approximations can be used to reduce this complexity. On the other hand, the chi-squared metric (Eq. (2)), which is a standard association routine, is straightforward in its computation. The target tracks provided the Kalman filter already have the associate state error covariance. A sensor model provides the conversion. One drawback with this method is that the uncertainty of the measurement is assumed to be Gaussian. Some implementations use a Gaussian sum approach (Alspach \& Sorenson, 1972) to approximate non-Gaussian distributions. This 
requires multiple iterations of the scoring routine followed by a weighting computation. A new Gaussian sum must be computed if blockage occurs on the sensor. A problem that underlies both the probability association approach and the chi-squared metric approach is that the implementations often do not incorporate the underlying probability that is necessary for the algorithms to provide accurate results. Often, the equations are employed without regard to an understanding of the probability distributions or, in the case of blockages and anomalies, the redistributions of the probability.

Another technique for the data association problem is to use basic fuzzy logic to provide the scoring mechanism. Fuzzy logic can utilize a linguistic/rule-based interpretation and implementation of the problem. The technique that will be described in the succeeding sections of this chapter is based on two interpretation of the widely-used chi-squared metric: a mathematical interpretation and a graphical interpretation. Its foundations for the basic Gaussian measurement to Gaussian track problem are then expanded to the problems where one of the two elements of the association pair is Gaussian and the other is of uniform distribution. This is followed by the case where both track and measurement are uniformly distributed. The applications of both hard constraints or boundary conditions and soft constraints are developed.

\section{Basic fuzzy logic}

Fuzzy logic is simply the mapping from an input measurement space to an output measurement using linguistic variables. It gives us the ability to model imprecisions by incorporating qualitative components into a quantitative analysis. Fuzzification is the process of mapping a numerical value into linguistic variables and associated degrees of membership. Defuzzification in contrast is the process of taking a consequence fuzzy membership function and creating a crisp value.

To develop fuzzy logic for the correlation of data, two sets of fuzzy membership functions, antecedent and conclusion (consequent), are required. A membership function is a function that maps the elements of the set to a value from 0 to 1 . The value to which the set is mapped is called the degree of membership. Each membership function for a fuzzy set relates to some knowledge base for that fuzzy set. For example, if the fuzzy set were temperature, the membership functions of hot, warm, and cold might be used. The range of temperatures would then be mapped into degrees of membership for each membership function. Figure 4 details these sets of membership functions. In Figure 4, the temperature 76 degrees has a degree of membership of 0.1 for cold, 0.6 for warm, and 0 for hot.

Figure 4 also demonstrates that all of the membership functions need not be the same shape or symmetric, although those characteristics are usually desirable to simplify the implementation. Another issue is the difference between inclusion of boundary points between the antecedent membership functions and the conclusion fuzzy sets. In antecedent sets, the extreme membership functions extend to infinity, as seen in Figure 5. Even if bounds exist on the antecedent fuzzy set, the extension will not have an adverse effect on the result. The conclusion function bounds are more important, however. As seen in Figure 6 , the output bounds are exceeded. One of the most useful properties of fuzzy sets is that crisp values can be given a fuzzy representation. A crisp value in an antecedent fuzzy set can be represented as a simple discrete unit impulse. For the consequence membership functions, the crisp value is represented as the Dirac delta function. 


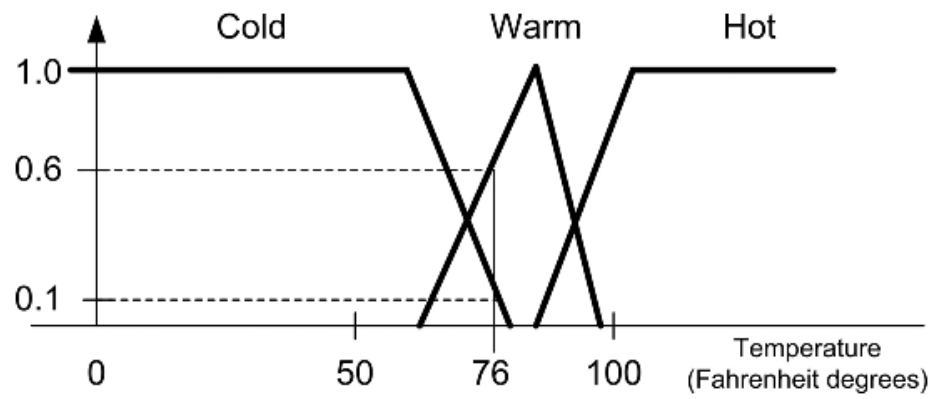

Fig. 4. Resulting reported kinematic measurements from platforms

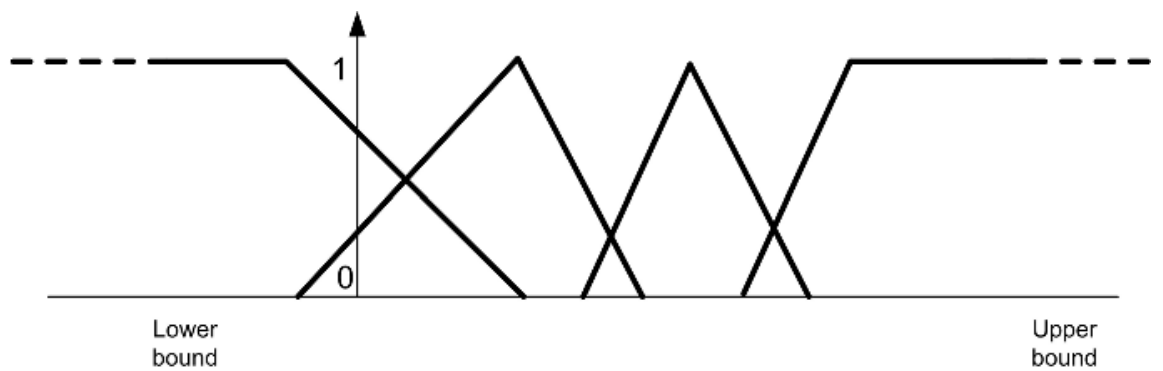

Fig. 5. Resulting reported kinematic measurements from platforms

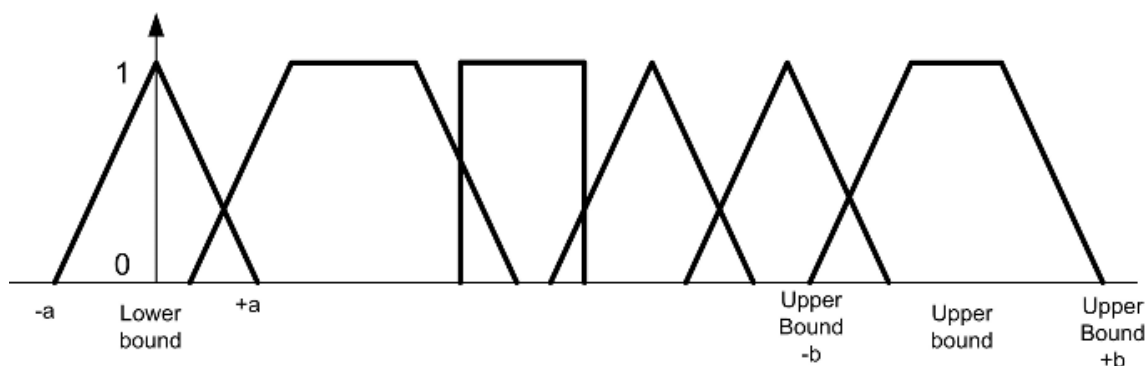

Fig. 6. Resulting reported kinematic measurements from platforms

If the function was defuzzified using the center of gravity method of Eq. (7), the bounds could not be achieved unless the center of the area of the extreme membership functions existed at the bounds. The position of the extreme bounds is determined by the defuzzification algorithm chosen. In the center of gravity technique,

$$
\operatorname{output}(t)=\frac{\sum_{i} \text { center }_{i} \cdot \text { area }_{i}}{\sum_{i} \text { area }_{i}}
$$

where center $_{i}$ is the center point of the $\mathrm{i}^{\text {th }}$ membership function and area $_{i}$ is the area of the $\mathrm{i}^{\text {th }}$ membership function. 


\section{Basic fuzzy data association}

There are a number of approaches to using fuzzy logic in the data association step for kinematic fusion. The approach developed here uses the chi-squared metric of Eq. (5) as the foundation. When this is done, the resulting association measure will be similar to the standard scoring algorithm when both the measurement and the track are Gaussian distributions. To create a fuzzy interpretation of the chi-squared metric, two interpretations of the association score are used: a mathematical interpretation and a graphical interpretation.

First, the chi-squared metric is considered a measure of the distance between two measurements: an estimated or predicted measurement and a reported measurement. The distance is weighted by the associated error covariances for each of these measurements. The covariance in the fuzzy logic association is used to scale the residuals or individual components of the Euclidian distance when they are mapped into the antecedent membership functions. This scaling relative to the context can be considered similar to the considerations of distances of golf as opposed to astronomy. The term close means in golf can mean a few inches while in astronomy it is considered in light years. Thus, the first fuzzy membership functions are developed based on the weighted residuals.

As seen in Figure 7, the parameters used to map the residual to the antecedent membership functions do not have fixed values. These parameters that define these membership functions are created using a fuzzy logic interpretation of the error covariance matrices and their related error ellipses. An error ellipse is an ellipse centered at the position mean of a measurement. The semi-major and semi-minor axes of the error ellipse are defined by the square root of the eigenvalues of the position covariance components of the error covariance matrices. The ellipse is oriented based on the eigenvectors. Using just the eigenvalues as the semi-axes creates a 1-sigma error ellipse. For this association approach, a 1.5-sigma error ellipse is used. An interpretation for the measurement covariance and an interpretation for the track covariance are both used to create and develop the parameter set, as seen in Figure 8. The parameter set is a weighted combination of the existing parameter set. This "layered" fuzzy approach is shown in Figure 9. By layering the fuzzy logic, two potential inputs to the association scoring inference engine are eliminated.

The second interpretation of the chi-squared metric is based graphically on the overlap of $n$ sigma ellipse of the track state and the measurement, as seen in an example in Figure 10. A percentage of overlap of the area of the measurement to the track covariance ellipse as well as the percentage of overlap area of the track to measurement covariance ellipse is calculated. The antecedent membership functions are shown in Figure 11. The two area measures along with the combined residual score form the three fuzzified inputs to the inference engine. A sample inference engine component for a residual of medium and the two overlap values is shown in Table 1.

In summary the five potential inputs have been reduced to three fuzzy inputs: the weighted residual, the percentage of measurement covariance overlap with the track covariance, and the percentage of the track covariance overlap with the measurement covariance. This is mapped through inference engines (Table 1) to an association score that is valued between 0 and 1 by defuzzifying the consequent resulting from Figure 12. 


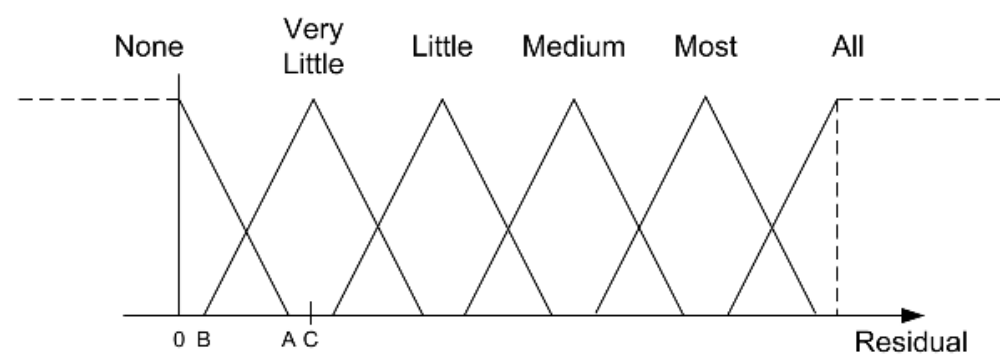

Fig. 7. Residual antecedent membership functions.


Fig. 8. Measurement and track covariances are used to determine a weighted parameter set through a fuzzy inference engine.

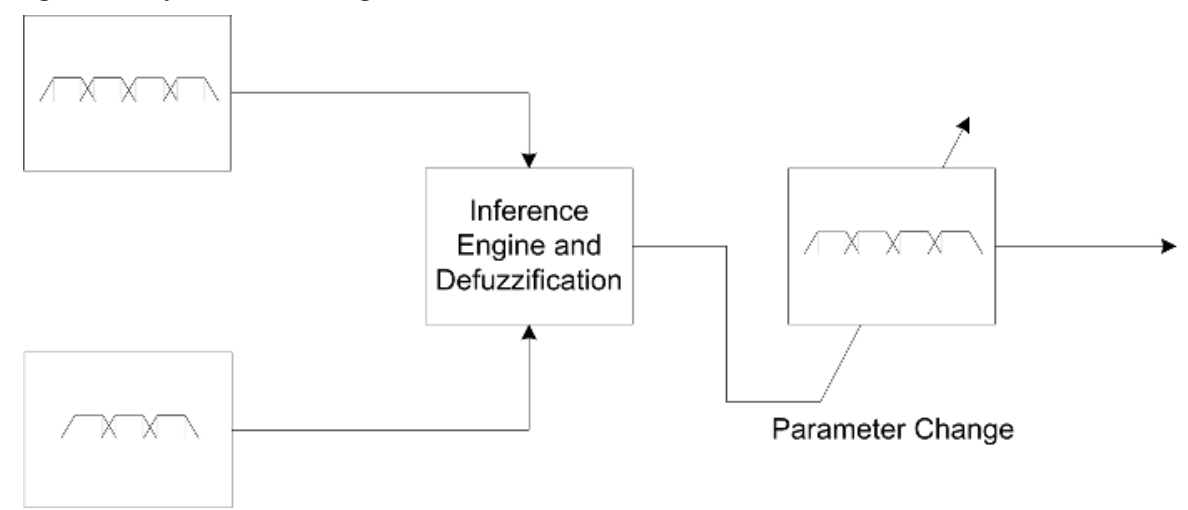

Fig. 9. A layered fuzzy system uses fuzzy logic to adjust the antecedent membership functions for another input. This reduces significantly the number of rules in the inference engines. 


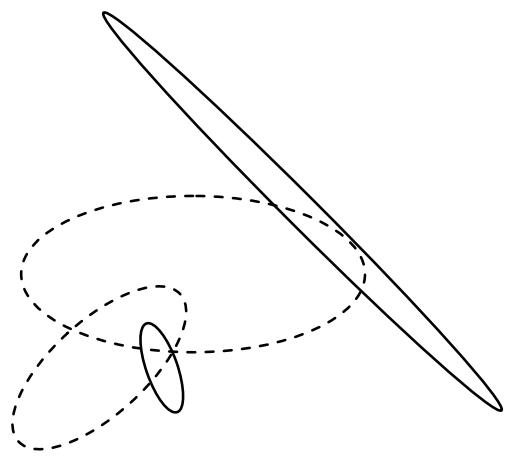

Fig. 10. Error ellipses approximate measurement and track Gaussian distributions. Here, two measurements (solid lines) overlap two tracks (dashed lines).

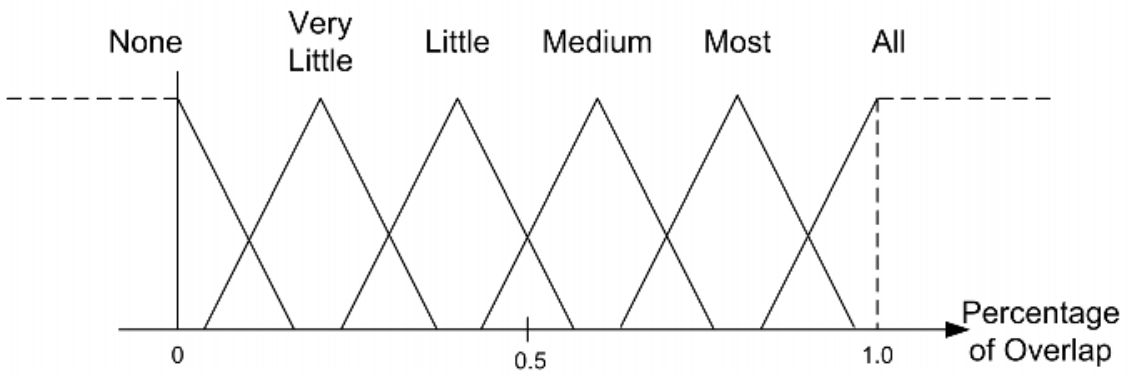

Fig. 11. Antecedent sets used to compute the association score for percentage of overlap of both track error ellipse and measurement error ellipse.

\begin{tabular}{|c|c|c|c|c|c|c|}
\hline Medium & None & $\begin{array}{l}\text { Very } \\
\text { Low }\end{array}$ & Low & Med. & Most & All \\
\hline None & $\begin{array}{l}\text { Very } \\
\text { Low }\end{array}$ & $\begin{array}{l}\text { Very } \\
\text { Low }\end{array}$ & $\begin{array}{l}\text { Very } \\
\text { Low }\end{array}$ & $\begin{array}{c}\text { Very } \\
\text { Low }\end{array}$ & $\begin{array}{c}\text { Very } \\
\text { Low }\end{array}$ & $\begin{array}{c}\text { Very } \\
\text { Low }\end{array}$ \\
\hline Very Low & $\begin{array}{l}\text { Very } \\
\text { Low }\end{array}$ & $\begin{array}{l}\text { Very } \\
\text { Low }\end{array}$ & $\begin{array}{l}\text { Very } \\
\text { Low }\end{array}$ & $\begin{array}{c}\text { Very } \\
\text { Low }\end{array}$ & Low & Low \\
\hline Low & $\begin{array}{l}\text { Very } \\
\text { Low }\end{array}$ & $\begin{array}{l}\text { Very } \\
\text { Low }\end{array}$ & Low & Low & Med & Med \\
\hline Med. & $\begin{array}{l}\text { Very } \\
\text { Low }\end{array}$ & $\begin{array}{l}\text { Very } \\
\text { Low }\end{array}$ & Low & Med & Med & High \\
\hline Most & $\begin{array}{l}\text { Very } \\
\text { Low }\end{array}$ & Low & Med & Med & High & $\begin{array}{c}\text { Very } \\
\text { High }\end{array}$ \\
\hline All & $\begin{array}{l}\text { Very } \\
\text { Low }\end{array}$ & Low & Med & High & $\begin{array}{l}\text { Very } \\
\text { High }\end{array}$ & $\begin{array}{c}\text { Very } \\
\text { High }\end{array}$ \\
\hline
\end{tabular}

Table 1. Element of Inference Engine to Map to Association Score Consequence Functions for a Uniform Measurement to Gaussian Track 


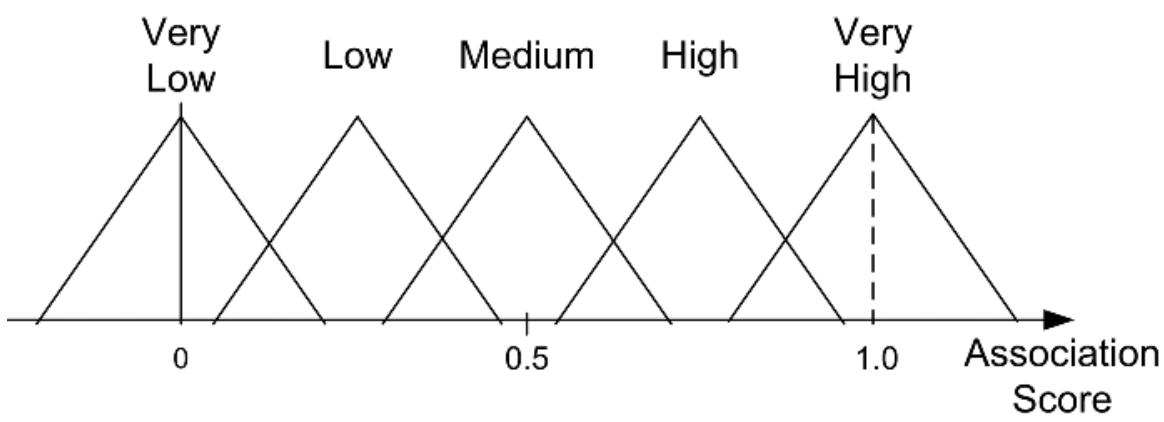

Fig. 12. Association score consequence membership functions.

\subsection{Algorithm outline}

The computation of the fuzzy data association score is performed using the following algorithm:

Step 1. Compute the semi-major and semi-minor axes and the rotation of the error ellipse defined by the covariance matrices of the tracks and the measurements. The values are a result of the eigenvalues and the orthonormal eigenvectors. This will define a 1-sigma error ellipse.

Step 2. Compute the points of the octagons approximation of the $n$-sigma error ellipse for the measurements and the tracks.

Step 3. For each track-measurement pair define the overlapping region of the error octagon approximations as set forth in the following steps:

Step $3 a$ Determine the intersection points of each a measurement octagon with a track octagon. This is done by computing the intersections of the lines that define the line segments of the octagons sides.

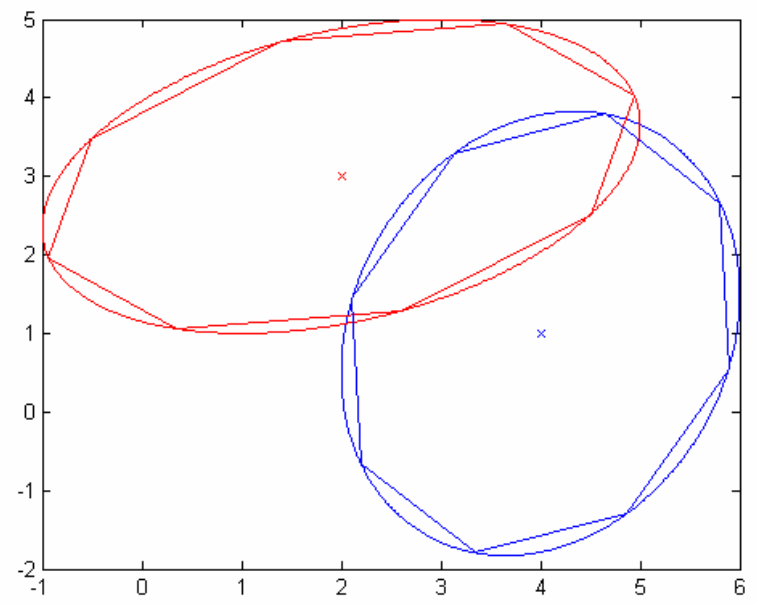

Fig. 13. Ellipses are approximated by octagons and the convex hull of their intersection is defined. 
Step $3 b$ Determine the vertices that may lie inside the other octagon such, as shown in Figure 13. This is done by determining taking each vertex separately of the measurement octagon placing it the track octagon and calculating if it creates a new convex hull. If a new convex hull is created then that vertex does not lie within the other octagon. The procedure is repeated by using the track vertices with the measurement octagon.

Step 4. Using the triangle area calculation of Heron's formula

$$
\text { area }=\sqrt{s(s-a)(s-b)(s-c)},
$$

where $a, b$, and $c$ are the vertices of the triangle and

$$
s=\frac{1}{2}(a+b+c),
$$

compute the area of the two octagons and the overlapping region as seen in Figure 14.

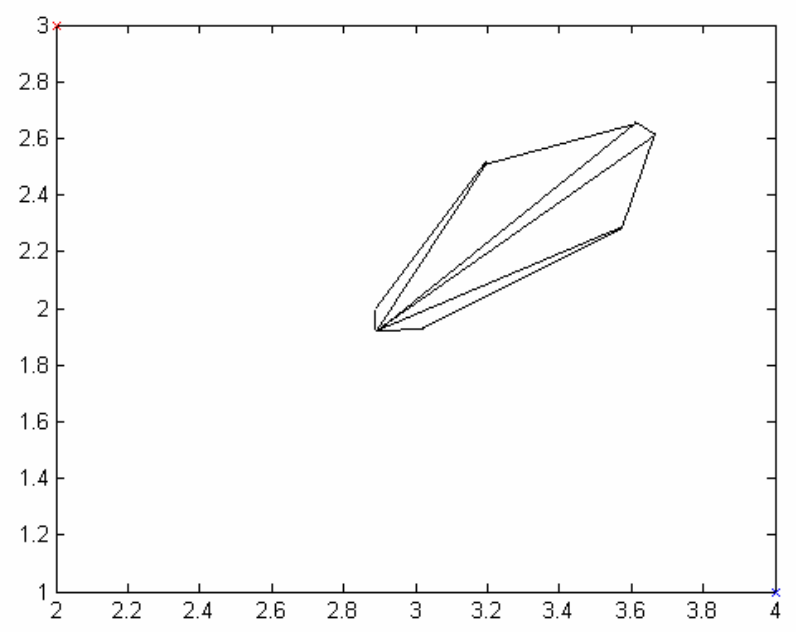

Fig. 14. The area of overlap between the two octagons is computed by dividing the polygon into triangles and applying Heron's formula.

Step 5. Compute the percentage of overlap for each covariance matrix.

Step 6. Using the layered fuzzy approach, which depends on the size of the covariances, define the degree of membership of the residual size. The covariances are used to generate the antecedent membership function parameters from an a priori set of parameters:

$$
\begin{aligned}
& \mathbf{P}_{1}=\left(a_{1}, b_{1}, c_{1}, \ldots\right) \\
& \mathbf{P}_{2}=\left(a_{2}, b_{2}, c_{2}, \ldots\right)
\end{aligned}
$$

using a fuzzy logic approach. 
Step 7. Employing the residual antecedent function from Step 7 define the degree of membership of the residual.

Step 8. Employing the antecedent membership functions, define the degree of memberships for the percentage of overlap for each of the octagons (track and measurement).

Step 9. Employ the inference engines with the three inputs, residual and two percentages of overlap, and the consequence membership functions to compute the score.

The functional flow of the algorithm is shown in Figure 15.

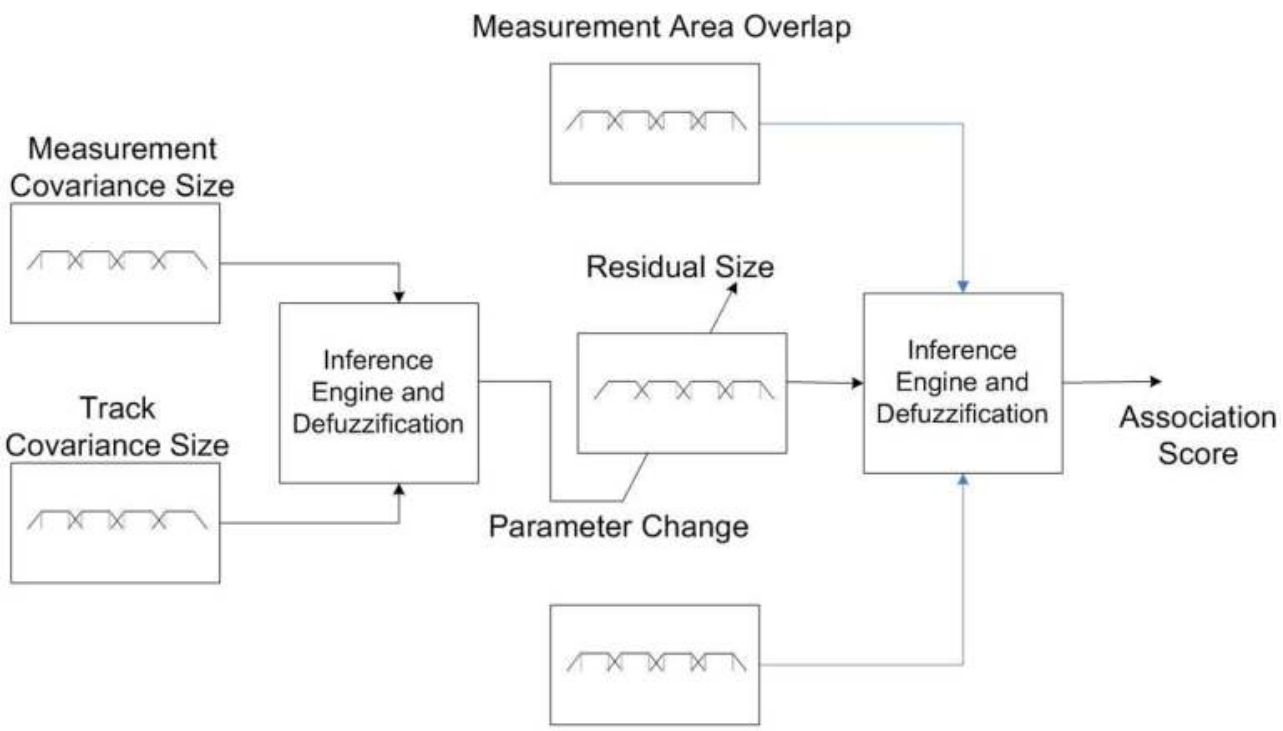

Track Area Overlap

Fig. 15. To reduce inference engine complexity, a layering of fuzzy logic provides the functional approach to chi-squared metric emulation.

\section{Fuzzy data association with uniform measurements}

One of the benefits of the fuzzy association approach is that it is not necessary that for either the measurements or the track to have a Gaussian distribution. With some minor modifications to the algorithm, the case of a uniform distribution, as happens with bearingsonly measurements, can be associated without using a Gaussian approximation.

\subsection{Fuzzy association for a Gaussian track and a uniform measurement}

The generation of the association score when the measurement is uniform can be performed in a manner quite similar to the algorithm outlined in Section 3.1. First, the semi-major and semi-minor axes and the rotation of the error ellipse defined by the covariance matrix of the track are computed in order to generate the 1-sigma error ellipse. The desired n-sigma error ellipse for the track is approximated by an octagon, while, for now, the uniform distribution is a rectangle. Use of more complex polygons can prove more accurate approximations to the uncertainty region. For each track-measurement pair, an overlapping region of the error octagon approximation and the uniform distribution is calculated. A pseudo-residual is 
computed, based on the average distance from the Gaussian mean to the uniform distribution, as in Figure 16. The covariance size of the track generates the parameters for the distance antecedent membership function. Antecedent membership functions such as those in Figure 17 define the degree of membership values for the percentage of overlap for the track's octagon and the measurement distribution. These fuzzy values fire the inference engines using the three inputs - the residual and two percentages of overlap. Table 2 shows an inference engine when the residual value is fuzzified to close.

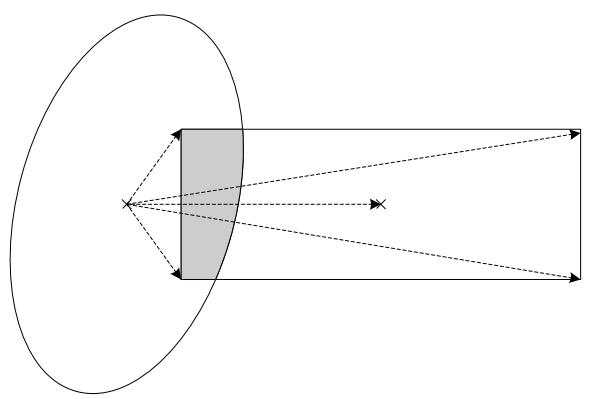

Fig. 16. Association of a Gaussian to a uniform distribution is dependent on both overlap and a modified residual.

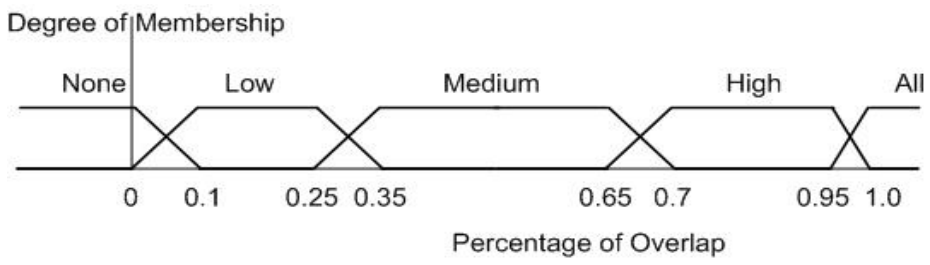

Fig. 17. Antecedent membership functions describe the percentage of overlap.

\begin{tabular}{|c|c|c|c|c|c|c|c|}
\hline \multirow{2}{*}{\multicolumn{2}{|c|}{$\begin{array}{c}\text { Relative } \\
\text { Distance Close }\end{array}$}} & \multicolumn{6}{|c|}{ Percentage of Gaussian Overlap } \\
\hline & & \multirow{2}{*}{$\begin{array}{l}\text { None } \\
\text { Very } \\
\text { Low }\end{array}$} & \multirow{2}{*}{$\begin{array}{l}\text { Very } \\
\text { Low } \\
\text { Very } \\
\text { Low }\end{array}$} & \multirow{2}{*}{$\begin{array}{l}\text { Low } \\
\text { Very } \\
\text { Low }\end{array}$} & \multirow{2}{*}{$\begin{array}{l}\text { Med } \\
\text { Very } \\
\text { Low }\end{array}$} & \multirow{2}{*}{$\begin{array}{l}\text { High } \\
\text { Very } \\
\text { Low }\end{array}$} & \multirow{2}{*}{$\begin{array}{c}\text { All } \\
\text { Very } \\
\text { Low }\end{array}$} \\
\hline$\frac{\overrightarrow{0}}{3}$ & None & & & & & & \\
\hline$\underset{\varepsilon}{\tilde{\varepsilon}}$ & $\begin{array}{l}\text { Very } \\
\text { Low }\end{array}$ & $\begin{array}{l}\text { Very } \\
\text { Low }\end{array}$ & $\begin{array}{l}\text { Very } \\
\text { Low }\end{array}$ & Low & Low & $\begin{array}{l}\text { Med } \\
\text { Low }\end{array}$ & $\begin{array}{l}\text { Med } \\
\text { High }\end{array}$ \\
\hline 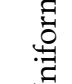 & Low & $\begin{array}{l}\text { Very } \\
\text { Low }\end{array}$ & Low & Low & $\begin{array}{l}\text { Med } \\
\text { Low }\end{array}$ & $\begin{array}{l}\text { Med } \\
\text { Low }\end{array}$ & High \\
\hline ? & Med. & Low & $\begin{array}{l}\text { Med } \\
\text { Low }\end{array}$ & $\begin{array}{l}\text { Med } \\
\text { Low }\end{array}$ & $\begin{array}{l}\text { Med } \\
\text { High }\end{array}$ & High & High \\
\hline$\underset{\Xi}{\mathbb{E}}$ & High & $\begin{array}{l}\text { Med } \\
\text { Low }\end{array}$ & $\begin{array}{l}\text { Med } \\
\text { High }\end{array}$ & $\begin{array}{l}\text { Med } \\
\text { High }\end{array}$ & High & High & $\begin{array}{l}\text { Very } \\
\text { High }\end{array}$ \\
\hline 过 & All & $\begin{array}{l}\text { Med } \\
\text { High }\end{array}$ & High & High & $\begin{array}{l}\text { Very } \\
\text { High }\end{array}$ & $\begin{array}{l}\text { Very } \\
\text { High }\end{array}$ & $\begin{array}{l}\text { Very } \\
\text { High }\end{array}$ \\
\hline
\end{tabular}

Table 2. Element of Inference Engine to Map to Association Score Consequence Functions for a Uniform Measurement to Gaussian Track 
The resulting membership functions are defuzzified to generate the association score. The consequence membership functions used are similar to those depicted in Figure 18.

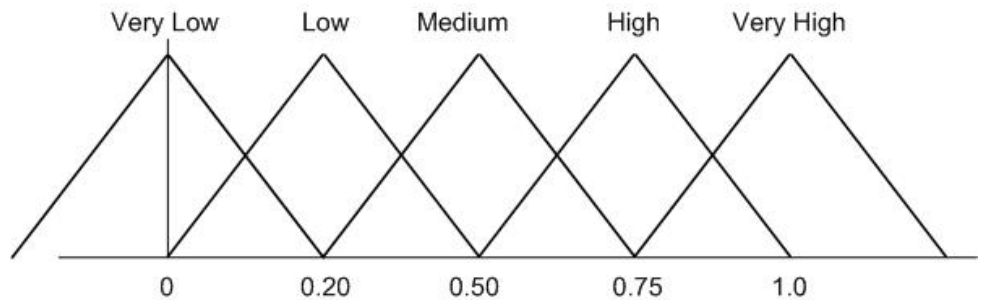

Fig. 18. Consequence membership functions used to develop the association score.

\subsection{Fuzzy association for a uniformly distributed track and a uniformly distributed measurement}

For the two uniform distributions case, the association problem degenerates into a simple problem of determining the area of overlap. First, the area of overlap for both the measurement and the track is computed. The percentage of overlap for each is then calculated. Fuzzification, using the antecedent membership functions similar to that of Figure 17, defines the degree of membership for the percentage of overlap for the track distribution and the measurement distribution. A single inference engine, such as shown in Table 3, maps the inputs to the consequence membership functions. The consequence membership functions shown in Figure 18 would also be suitable for this case. Defuzzifying the resulting membership function computes the resulting association score.

\begin{tabular}{|c|c|c|c|c|c|c|c|}
\hline & \multicolumn{6}{|c|}{ Percentage of Measurement 1 Overlap } \\
\hline & & None & $\begin{array}{l}\text { Very } \\
\text { Low }\end{array}$ & Low & Med & High & All \\
\hline \multirow{6}{*}{ 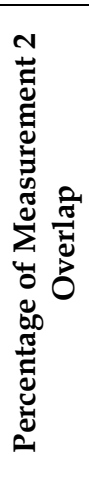 } & None & $\begin{array}{l}\text { Very } \\
\text { Low }\end{array}$ & $\begin{array}{l}\text { Very } \\
\text { Low }\end{array}$ & Low & Low & $\begin{array}{l}\text { Med } \\
\text { Low }\end{array}$ & $\begin{array}{l}\text { Med } \\
\text { Low }\end{array}$ \\
\hline & $\begin{array}{l}\text { Very } \\
\text { Low }\end{array}$ & $\begin{array}{l}\text { Very } \\
\text { Low }\end{array}$ & $\begin{array}{l}\text { Very } \\
\text { Low }\end{array}$ & Low & Low & $\begin{array}{l}\text { Med } \\
\text { Low }\end{array}$ & $\begin{array}{l}\text { Med } \\
\text { Low }\end{array}$ \\
\hline & Low & Low & Low & Low & $\begin{array}{l}\text { Med } \\
\text { High }\end{array}$ & $\begin{array}{l}\text { Med } \\
\text { High }\end{array}$ & $\begin{array}{l}\text { Med } \\
\text { High }\end{array}$ \\
\hline & Med & Low & $\begin{array}{l}\text { Med } \\
\text { Low }\end{array}$ & $\begin{array}{l}\text { Med } \\
\text { High }\end{array}$ & $\begin{array}{l}\text { Med } \\
\text { High }\end{array}$ & $\begin{array}{l}\text { Med } \\
\text { High }\end{array}$ & High \\
\hline & High & $\begin{array}{l}\text { Med } \\
\text { Low }\end{array}$ & $\begin{array}{l}\text { Med } \\
\text { Low }\end{array}$ & $\begin{array}{l}\text { Med } \\
\text { High }\end{array}$ & $\begin{array}{l}\text { Med } \\
\text { High }\end{array}$ & High & $\begin{array}{l}\text { Very } \\
\text { High }\end{array}$ \\
\hline & All & $\begin{array}{l}\text { Med } \\
\text { Low }\end{array}$ & $\begin{array}{l}\text { Med } \\
\text { Low }\end{array}$ & $\begin{array}{l}\text { Med } \\
\text { High }\end{array}$ & High & $\begin{array}{l}\text { Very } \\
\text { High }\end{array}$ & $\begin{array}{l}\text { Very } \\
\text { High }\end{array}$ \\
\hline
\end{tabular}

Table 3. Inference Engine to Map to Association Score Consequence Functions for a Uniform Measurement to a Uniform Track

\section{Fuzzy data association in the presence of constraints}

The fuzzy association routine can be augmented to accommodate a variable scale target location region. As seen in Figure 19, information such as bathymetric data could influence 
the location possibilities of a submarine or a ship (National Geophysical Data Center, 2007). Deep draft ships and submarines often avoid shallows that could endanger the vessel and or mission. Thus, various depths would weight the effectiveness of uncertainty differently based on the locations. So in Figure 20, the uncertainty ellipses of a track or measurement would be less pronounced near the shores and over the seamounts where operations would be less likely. Such measurements would better fit with littoral-active vessels. The channels would be much likely operations for the vessels in question. The incorporation of this new information is incorporated by creating a weighting to the component of the area of overlap in the fuzzy association routine. The weighting is generated using a fuzzy scoring technique. The added information improves the performance of the association routine based in a global sense.

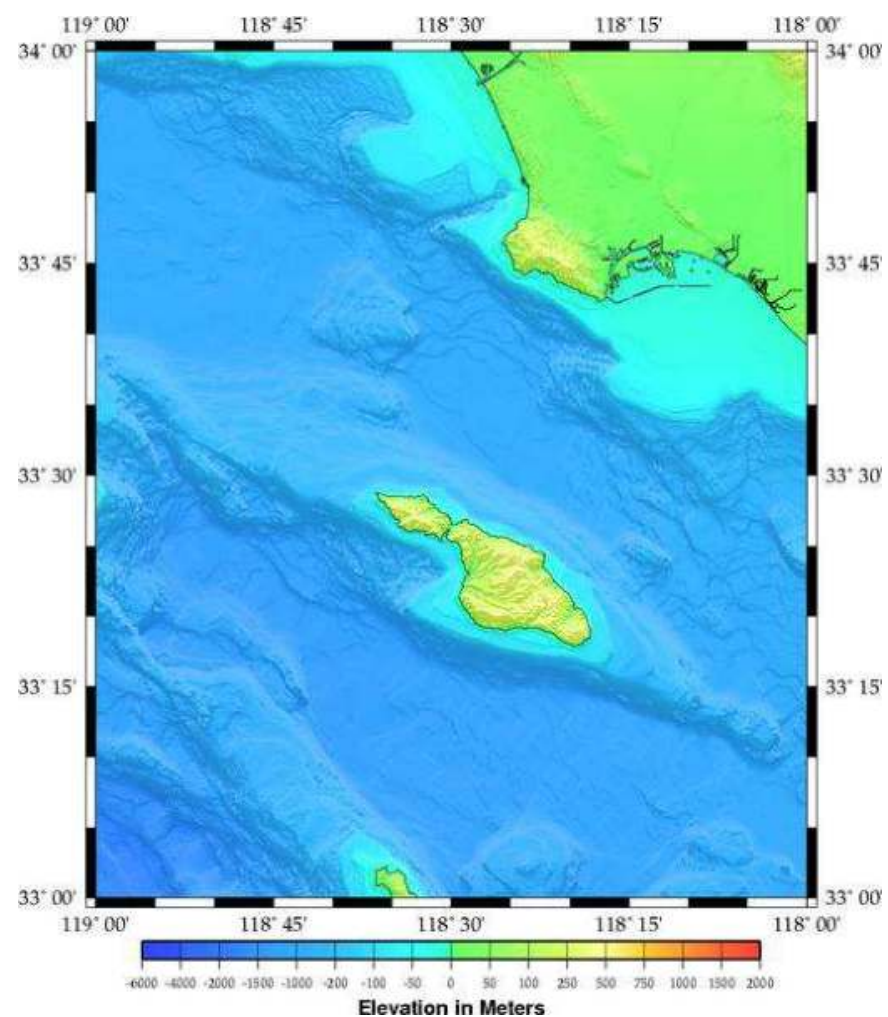

Fig. 19. Bathymetric data influences feasible track space of a vessel.

\subsection{Fuzzy association with hard constraints}

If sensor blockage or target prohibition is present, the covariance ellipses can be modified accordingly to incorporate the constraint. Figure $w w+4 a$ details the reduction of the error ellipse area based on senor blockage of the sensor and prohibited terrain for the target. The new area considered for overlap is shown in Figure 20b. These are considered hard constraints in that the regions are removed. The remaining feasible regions can be mapped similar to the redistribution of the Dempster-Schafer concept (Dempster, 1967) or by a 
simple reduction in area. The steps of the algorithm remain the same if area is removed due to sensor blockage or terrain prohibitions. Only the percentages of overlap change.

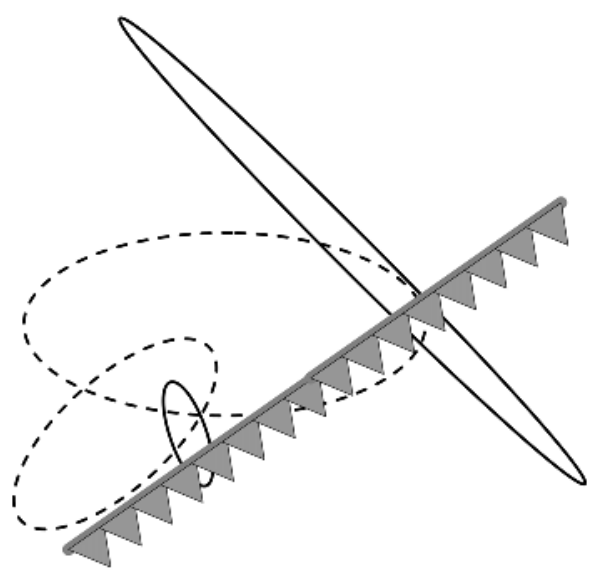

(a)

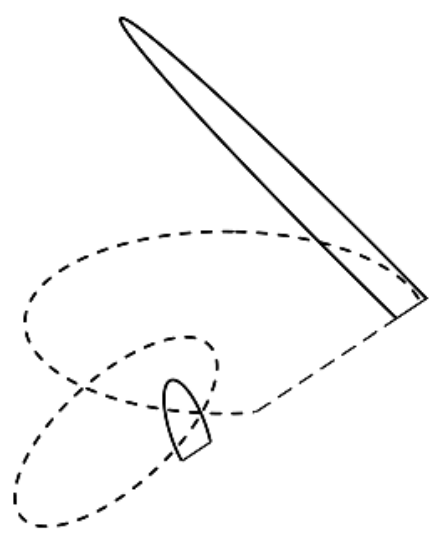

(b)

Fig. 20. Uncertainty error ellipses are affected by sensor blockage. a) Gaussian ellipses and blockage indicated; b) resulting alteration of ellipse.

\subsection{Incorporation of soft constraints for fuzzy association - the penalty method}

In Figure 21, shading is used to indicate four distinct regions where the target can operate with the measurement and the track uncertainty ellipses overlaying these. These regions might be used to reflect operational conditions, such as indicating the depth that a submarine can operate in the specific regions. Since stealth is the submarines primary

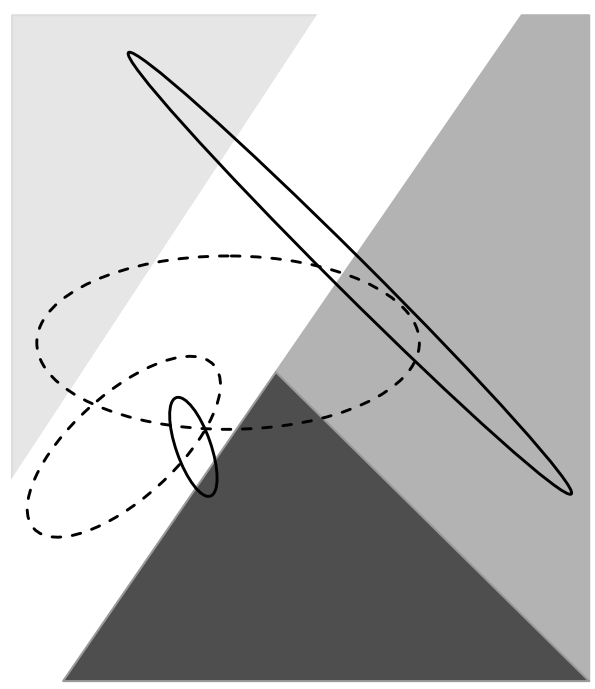

Fig. 21. Measurement and track ellipses span distinct regions of operation. 
defense, operations in the shallows, where visual spotting becomes more likely, are less probable. So the different regions of overlap indicate that the area of overlap used by the fuzzy association algorithm should be reduced in a systematic way. The penalty method approach is based on the concept of discrete regions of target possibility or sensor capability. The approach proposed is to use a weighting scheme that maps the operational parameters into the environmental reports to create a weight. Since much of the information is heuristic in nature, the use of a fuzzy logic mapping for this weighting is proposed.

Figure 22 presents a chi-squared emulation with the added component of the penalty function. As shown, the weighting adapts the area of overlap using a fuzzy logic system. The complexity of the component varies significantly depending on the knowledge of the target type, the environment, and the sensor system.

As discussed in (Stimson, 1998) and (Hall \& Linus, 2001), the sensor systems are often well understood with the physical capabilities well defined. The operational environment is somewhat less understood but often known to a good degree so that the mission can be successful. Finally, while the target capabilities may be well known, the actual classification of the target to use such data is not often available. A library of information can be used to generate membership functions a priori for each component of knowledge. The level of uncertainty associated with the knowledge component will be combined into the final score that will drive the adaptation weighting. This is shown in Figure 23.

The implementation of this penalty based routine is created by implementing the following algorithm:

Step 1. Compute the semi-major and semi-minor axes and the rotation of the error ellipse defined by the covariance matrices of the tracks and the measurements. This is performed by generating the eigenvalues and eignevectors of the covariance matrices. This will define a 1-sigma error ellipse.

Step 2. Approximate the $n$-sigma error ellipses for both the measurement and the track by octagons. Compute the vertices of the octagons.

Step 3. For each track-measurement pair, define the overlapping region of the error by using at least an octagon approximation to each area as set forth in the following steps:

Step $3 a$ Determine the intersection points of each measurement octagon with a track octagon by computing the intersections of the lines that define the line segments of the sides of the octagon.

Step $3 b$ Determine the vertices that may lie inside the other octagon by taking each vertex of the measurement octagon separately and calculating if it creates a new convex hull with the track octagon.

If a new convex hull is created, then that vertex does not lie within the other octagon. The procedure is repeated by using each of the track vertices with the measurement octagon.

Step $3 c$ Approximate the constraint boundary condition as exemplified in Figure 5 with a piece-wise linear approximation.

Step $3 d$ Define the multiple irregular polygons for each operational region using the vertices defined in Step 3c and 3d.

Step 4. Using the triangle area calculation of Heron's formula

$$
\text { area }=\sqrt{s(s-a)(s-b)(s-c)},
$$


where $a, b$, and $c$ are the vertices of the triangle and

$$
s=\frac{1}{2}(a+b+c) \text {, }
$$

the area of the two octagons and the overlapping region is then computed by summing the areas of the triangles.

Area Restrictions

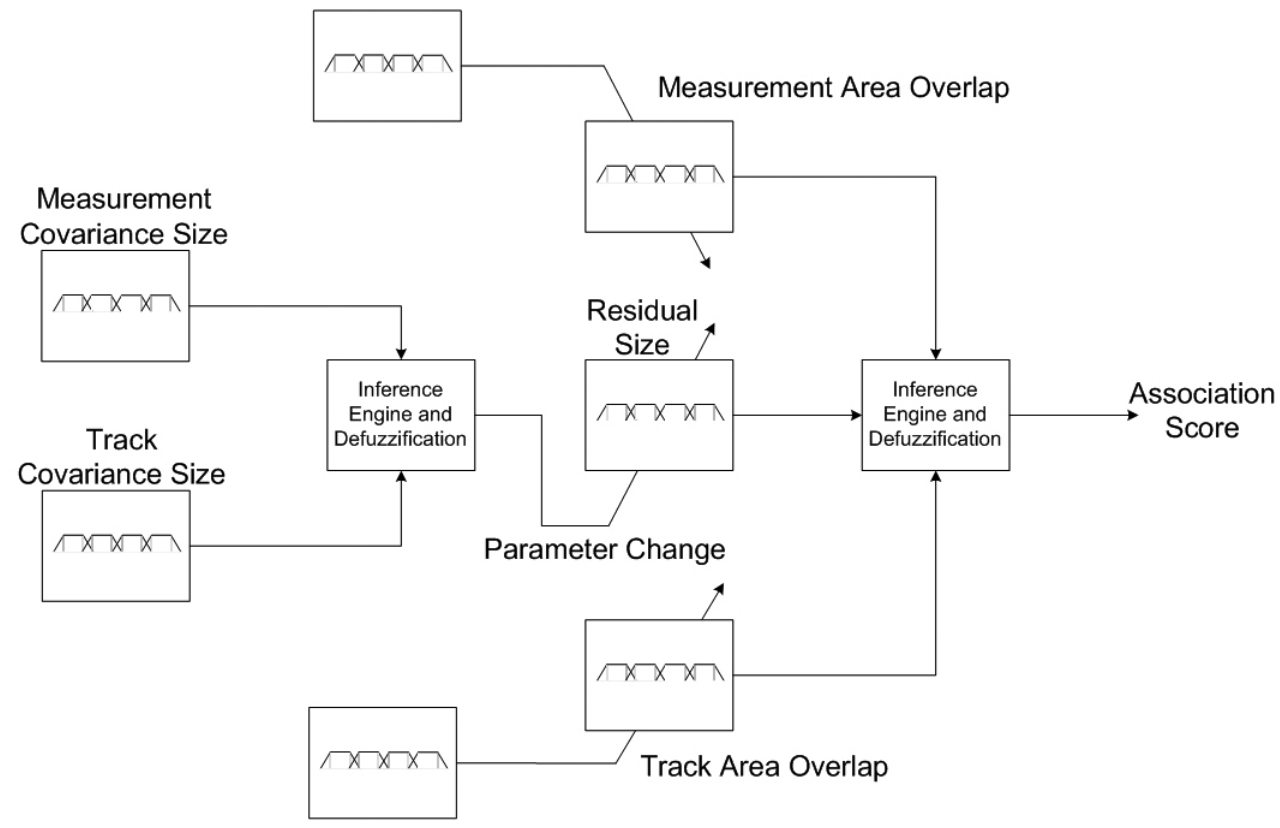

Area Restrictions

Fig. 22. Penalty function augments determination of overlap.

Component

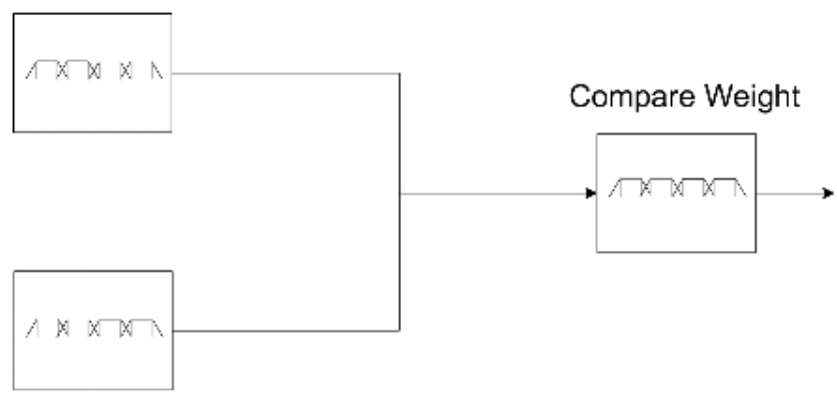

Uncertainty

Fig. 23. Level of uncertainty combines into final score. 
Step 5. Compute the percentage of overlap for each covariance matrix using penalty method approach:

Step $5 a$ Using layered fuzzy logic as in Figure 7, the information from the different constraint components and their uncertainties create a component weight which then is fed as input to the fuzzy systems to create the area restriction weight for each region defined in Step 3d.

Step $5 b$ Compute the weighted area

$$
\text { area }=\sum_{i=1}^{\# \text { of regions }} w_{i} \text { area }_{i}
$$

and incorporate that into percentage of overlap:

$$
\text { percent }=\left(\operatorname{area} / \prod \operatorname{eig}(\mathbf{R})\right) \cdot 100
$$

Step 6. Using the layered fuzzy approach shown in Figure kk+1, which depends on the size of the covariances, define the degree of membership of the residual size. Antecedent membership functions provide the fuzzification of the error covariances. The inference engine then maps input to the consequence membership functions. Each parameter defines a set of parameters for each of the membership functions which provide the parameters that describe the antecedent membership functions for the residual.

Step 7. Employing the antecedent membership functions for overlap, the degree of memberships for the percentage of overlap for each of the octagons (track and measurement) is defined.

Step 8. Employing the inference engines with the three inputs, residual and two percentages of overlap as described above.

Step 9. Defuzzify the resulting membership function to generate the association score. The consequence membership functions are used to compute the score.

\section{Association example with constraints}

To demonstrate the implementation of the association concept an example with constraints is shown. The implementation of this complex example is shown for the three cases: no constraint, a hard constraint, and soft constraints.

The typical passive fixed-sonar array provides a superb example for the use of the softconstraint fuzzy association routine. Depending on the deployment of the line array and its final settling point on the sea bottom, the capabilities of sonar for different bearing angles varies. In Figure 24, a simulated example of an array's direct blast zone is shown. Because of line distortions as the result of nonlinear deployment and sea-bottom features which block sound propagation to some or all of the receivers, the acoustic capabilities change. The darker regions indicate less reception capabilities for the array. A fixed line array also has the problem that sign of the angle of the acoustic source from the sonar cannot always be determined. Thus, a mirror image of the true measurement is also generated.

Figure 25 shows a three target example for the sonar array defined in Figure 24 with the boundaries of the capability regions are overlaid. The measurement is a bearings-only 
measurement with ambiguity. The associated uncertainty is defined by the solid ellipses. The track uncertainties are defined by the dashed lines. The uncertainty ellipses and track locations are defined in Table 4 for the three targets. The center of the direct blast convergence zone is considered to be origin of the region. As an ambiguous line of bearing, the measurement is approximated by a single Gaussian with its uncertainty ellipse defined in Table 5.

Figure 26 defines the antecedent membership functions based on the capabilities. Figure 27 defines the consequence membership functions to generate weighting functions for the areas of overlap.

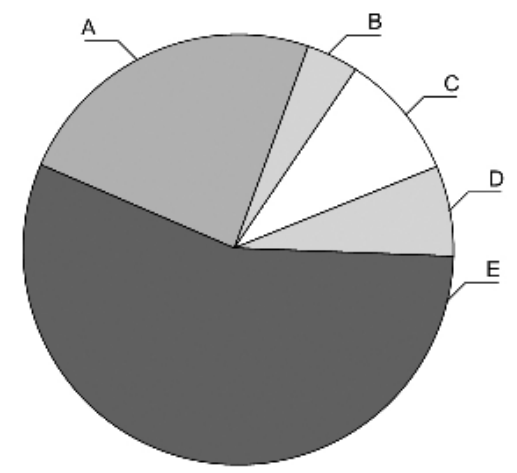

Fig. 24. Array has varying levels of reception (with darker regions indicating poorer reception) over direct blast zone.

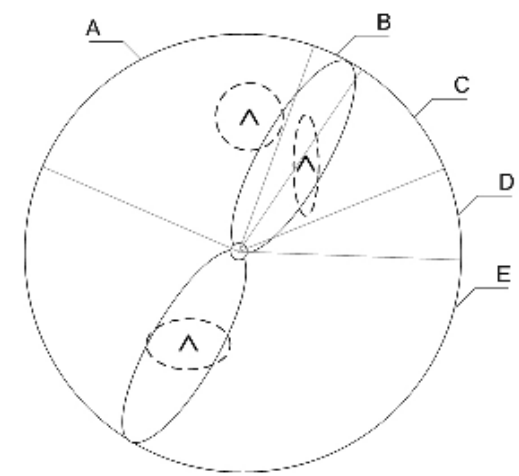

Fig. 25. Example with three targets in array region with varying levels of reception.

\begin{tabular}{|c|c|c|c|c|c|}
\hline $\begin{array}{c}\text { Track } \\
\text { no. }\end{array}$ & $\begin{array}{c}\text { x-coord } \\
(\mathrm{NM})\end{array}$ & $\begin{array}{c}\text { y-coord } \\
(\mathrm{NM})\end{array}$ & $\begin{array}{c}\text { Semi-major } \\
\text { axis (NM) }\end{array}$ & $\begin{array}{c}\text { Semi-minor } \\
\text { axis (NM) }\end{array}$ & $\begin{array}{c}\text { Angle } \\
(\mathrm{deg})\end{array}$ \\
\hline 1 & 7.69 & 9.85 & 5.77 & 1.45 & 90 \\
\hline 2 & 1.23 & 15.38 & 3.85 & 3.85 & 0 \\
\hline 3 & -5.69 & -10.62 & 4.81 & 2.89 & 0 \\
\hline
\end{tabular}

Table 4. Target track locations and uncertainties 


\begin{tabular}{|c|c|c|c|c|c|}
\hline $\begin{array}{c}\text { Meas. } \\
\text { no. }\end{array}$ & $\begin{array}{c}\text { x-coord } \\
(\mathrm{NM})\end{array}$ & $\begin{array}{c}\text { y-coord } \\
(\mathrm{NM})\end{array}$ & $\begin{array}{c}\text { Semi- } \\
\text { major axis } \\
(\mathrm{NM})\end{array}$ & $\begin{array}{c}\text { Semi- } \\
\text { minor axis } \\
(\mathrm{NM})\end{array}$ & $\begin{array}{c}\text { Angle } \\
(\mathrm{deg})\end{array}$ \\
\hline 1 & 6.31 & 10.92 & 12.5 & 3.85 & 60 \\
\hline 2 & -6.31 & -10.92 & 12.5 & 3.85 & 240 \\
\hline
\end{tabular}

Table 5. Measurement locations with an ambiguous detection

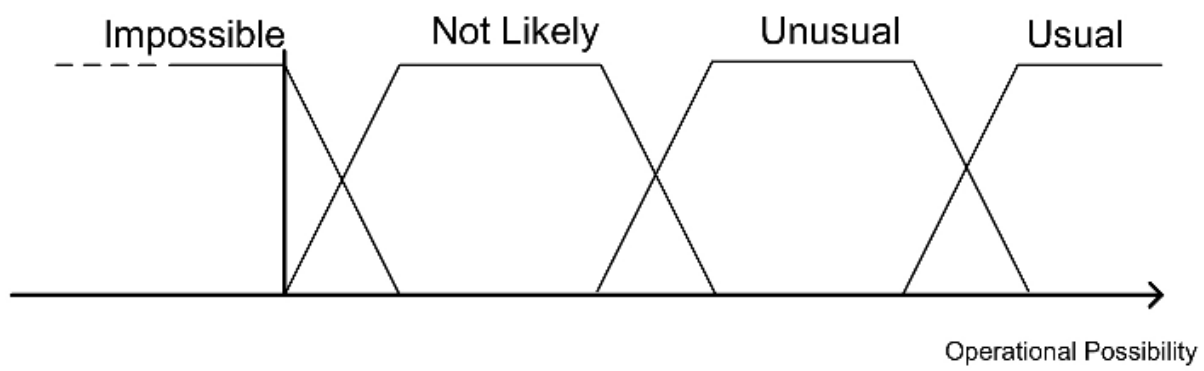

Fig. 26. Antecedent membership functions for possibility of a target in a region

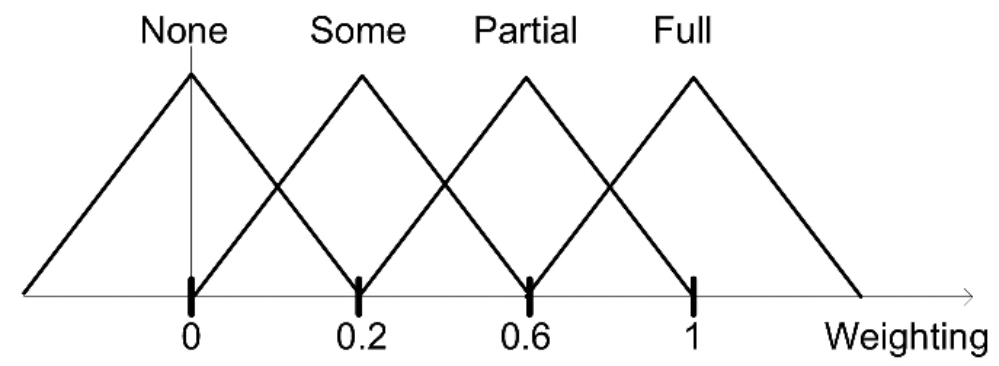

Fig. 27. Consequence membership functions for the weighting based on soft constraints.

The inference engine is defined as

\begin{tabular}{c|c|c|c|c}
$\begin{array}{c}\text { Track } \\
\text { Existence }\end{array}$ & Impossible & $\begin{array}{c}\text { Not } \\
\text { Likey }\end{array}$ & Unusual & Usual \\
\hline & None & Some & Partial & Full
\end{tabular}

For the hard constraint case, the inference engine is defined as

\begin{tabular}{c|c|c|c|c}
$\begin{array}{c}\text { Track } \\
\text { Existence }\end{array}$ & Impossible & $\begin{array}{c}\text { Not } \\
\text { Likely }\end{array}$ & Unusual & Usual \\
\hline & None & None & Full & Full
\end{tabular}

The results for the soft-constraint or penalty method approach for association are compared in Table 6. They are compared against those of the normalized chi-squared technique, the standard fuzzy association method, and the hard-constraint or barrier method. 


\begin{tabular}{|c|c|c|c|c|}
\hline & Chi-Squared & $\begin{array}{c}\text { Fuzzy } \\
\text { Association }\end{array}$ & $\begin{array}{c}\text { Fuzzy Assoc. } \\
\text { with } \\
\text { Constraints }\end{array}$ & $\begin{array}{c}\text { Fuzzy } \\
\text { Assoc. with } \\
\text { Penalty }\end{array}$ \\
\hline Target 1 & 0.767 & 0.637 & 0.637 & 0.58 \\
\hline Target 2 & 0.024 & 0.083 & 0 & 0.008 \\
\hline Target 3 & 0.9252 & 0.841 & 0 & 0 \\
\hline
\end{tabular}

Table 6. Association scores based on the normalized chi-squared and the three fuzzy association techniques

The results for this example case clearly indicate that use of constraints provides improved association scoring as the non-possible solutions are eliminated. The soft-constraint approach has the advantage over the use of hard-constraints in that improbable solutions still appear but with a lower score. This is of use in multi-hypothesis tracking systems and $\mathrm{N}$-dimensional-assignment based systems.

\section{References}

Hall, D. \& Llinas, J. , (2001). Handbook of Multisensor Data Fusion, CRC Press, Boca Raton.

Steinberg A. ; Bowman, C., \& White, F. , (1999). "Revisions to the JDL Data Fusion Model", Proceedings of the SPIE Sensor Fusion: Architectures, Algorithms, and Applications III, pp 430-441, Orlando, FL, March, 1999.

Blackman, S., (1986). Multiple-Target Tracking with Radar Applications, Artech House, Norwood, MA.

Blackman, S. \& Popoli, R. , (1999). Design and Analysis of Modern Tracking Systems, Artech House, Norwood, MA.

Bar-Shalom, Y. \& Li, X.-R., (1993). Estimation and Tracking: Principles, Techniques, and Software, Artech House Inc., Norwood, MA.

Alspach, D. \& Sorenson, H., (1972). “Nonlinear Bayesian Estimation Using Gaussian Sum Approximations," IEEE Transactions on Automatic Control, Vol. 17 , No. 4 , pp. 439 448, Aug., 1972.

National Geophysical Data Center, Geophysical Search and Data Retrieval System, (2007).

Bar-Shalom, Y. \& Tse, E., (1975)." Tracking in a Cluttered Environment with Probabilistic Data Association," Automatica, 11, Sep., 1975, pp. 451-460.

Priebe, R. \& Jones, R., (1991). "Fuzzy Logic Approach to Multi-Target Tracking in Clutter," Proc. of SPIE, Vol. 1482, Acquisition, Tracking, and Pointing V, pp. 265-274, Orlando, $\mathrm{Fl}$, March, 1991.

Lefebvre, E. \& Helleur, C., (2002). "Use of Fuzzy Logic for Data Fusion in a Recognized Maritime Picture," Advances in Intelligent Systems, Fuzzy Systems, Evolutionary Computation (Proc. of the 3rd WSES International Conference on Fuzzy Sets and Fuzzy Systems), pp. 24-29, Interlaken, Switzerland, Feb, 2002.

Dempster, A.P., (1967). “Upper and Lower Probabilities Induced by a Multivalued Mapping," Annals of Mathematical Statistics, 38, 1967, pp. 325 - 339.

Stimson, G.W. , (1998). Introduction to Airborne Radar: Second Edition, Scitech Publishing, Inc., Mendham, New Jersey. 
Stubberud, S.C. \& Kramer, K.A., (2006). “Data Association for Multiple Sensor Types Using Fuzzy Logic," IEEE Transactions on Instrumentation and Measurement, Vol. 55, No. 6, pp. 2292-2303, Dec., 2006. 


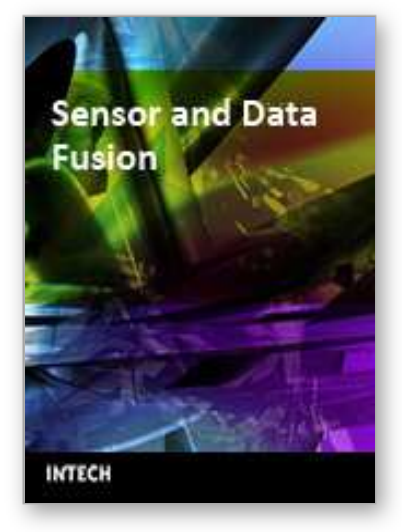

\author{
Sensor and Data Fusion \\ Edited by Nada Milisavljevic
}

ISBN 978-3-902613-52-3

Hard cover, 436 pages

Publisher I-Tech Education and Publishing

Published online 01, February, 2009

Published in print edition February, 2009

Data fusion is a research area that is growing rapidly due to the fact that it provides means for combining pieces of information coming from different sources/sensors, resulting in ameliorated overall system performance (improved decision making, increased detection capabilities, diminished number of false alarms, improved reliability in various situations at hand) with respect to separate sensors/sources. Different data fusion methods have been developed in order to optimize the overall system output in a variety of applications for which data fusion might be useful: security (humanitarian, military), medical diagnosis, environmental monitoring, remote sensing, robotics, etc.

\title{
How to reference
}

In order to correctly reference this scholarly work, feel free to copy and paste the following:

Stephen Stubberud and Kathleen Kramer (2009). Target Data Association Using a Fuzzy-Logic Based Approach, Sensor and Data Fusion, Nada Milisavljevic (Ed.), ISBN: 978-3-902613-52-3, InTech, Available from: http://www.intechopen.com/books/sensor_and_data_fusion/target_data_association_using_a_fuzzylogic_based_approach

\section{INTECH}

open science | open minds

\section{InTech Europe}

University Campus STeP Ri Slavka Krautzeka 83/A 51000 Rijeka, Croatia Phone: +385 (51) 770447

Fax: +385 (51) 686166 www.intechopen.com

\section{InTech China}

Unit 405, Office Block, Hotel Equatorial Shanghai No.65, Yan An Road (West), Shanghai, 200040, China 中国上海市延安西路65号上海国际贵都大饭店办公楼 405 单元 Phone: +86-21-62489820

Fax: $+86-21-62489821$ 
(C) 2009 The Author(s). Licensee IntechOpen. This chapter is distributed under the terms of the Creative Commons Attribution-NonCommercialShareAlike-3.0 License, which permits use, distribution and reproduction for non-commercial purposes, provided the original is properly cited and derivative works building on this content are distributed under the same license. 